\title{
A Utilização das Tic's no Ensino de História
}

\author{
La utilización de las tic's en la enseñanza de Historia \\ The use of ict's in the teaching of History
}

\author{
Simone Weber Cardoso Schneider ${ }^{1}$ \\ Adriana Duarte Leon ${ }^{2}$
}

\begin{abstract}
Resumo
Vivemos atualmente em um mundo com diversas tecnologias digitais, o que ocasiona mudanças no nosso modo de relacionamento, trabalho, comunicação e estudo. A escola não fica imune a essas mudanças e as Tecnologias de Informação e Comunicação (TIC's), chegam também no espaço escolar. Compreendemos que os recursos tecnológicos podem auxiliar na prática pedagógica, motivando os alunos na construção do conhecimento histórico. Considerando tal afirmação este artigo faz uma breve retrospectiva sobre o Ensino de História no Brasil e uma revisão bibliográfica sobre o tema. Julgamos este estudo relevante, tendo em vista o reconhecimento, por parte dos professores, sobre a potencialidade das Tic's como ferramenta auxiliar ao processo de ensino e aprendizagem. Ainda assim, percebemos algumas barreiras que precisam ser superadas, como a falta de formação continuada para que o professor utilize esse recurso e a falta de infraestrutura adequada nas escolas. Pretendemos, com este estudo, colaborar com o debate acerca da utilização das tecnologias no Ensino de História, suas possibilidades e desafios na contemporaneidade.
\end{abstract}

Palavras-Chave: Ensino de história; Prática pedagógica, Tecnologias.

\section{Resumen}

Vivimos actualmente en un mundo con diversas tecnologías digitales, lo que ocasiona cambios en nuestro modo de relacionamiento, trabajo, comunicación y estudio. La escuela no queda inmune a estos cambios y las Tecnologías de Información y Comunicación (TIC'S), llegan también en el espacio escolar. Comprendemos que los recursos tecnológicos pueden auxiliar en la práctica pedagógica, motivando a los alumnos en la construcción del conocimiento histórico. Considerando tal afirmación este artículo haz una breve retrospectiva sobre la Enseñanza de Historia en Brasil y una revisión bibliográfica sobre el tema. Juzgamos este estudio relevante, teniendo en vista el reconocimiento, por parte de los profesores, sobre la potencialidad de las Tic's como herramienta auxiliar en el proceso de enseñanza y aprendizaje, Todavía así, percibimos algunas barreras que necesitan ser superadas, como la falta de formación continuada para que el profesor utilice este recurso y la falta de infraestructura adecuada en las escuelas. Pretendemos, con este estudio, colaborar con el debate acerca de la utilización de las tecnologías en la Enseñanza de Historia, sus posibilidades y desafíos en la contemporaneidad.

Palabras claves: Enseñanza de Historia, Práctica pedagógica; Tecnologías.

\begin{abstract}
This We currently live in a world with diverse digital technologies, which causes changes in our way of relationship, work, communication and study. The school is not immune to these changes and Information and Communication Technologies (ICTs) also arrive in the school space. We understand that technological resources can assist in pedagogical practice, motivating students in the construction of historical knowing. Considering this affirmation, this article makes a brief retrospective on History Teaching in Brazil and a bibliographic review on the theme. We believe this relevant study, in view of the recognition, on the part of teachers, of the potential of

\footnotetext{
${ }^{1}$ Mestranda do Programa de Mestrado Profissional em Educação e Tecnologias, Instituto Federal Sul RioGrandense (IFSUL), Pelotas, Rio Grande do Sul, Brasil, simonewcs@ gmail.com

${ }^{2}$ Doutora em Educação pela UFMG, Mestre em Educação pela UFPEL, Professora atuando no MPET/IFSUL, linha de pesquisa: "Educação, Cultura e Trabalho", Pelotas, Rio Grande do Sul, Brasil, adriana.adrileon@gmail.com.
} 
ICT's as an auxiliary tool to the teaching and learning process. Even so, we perceive some barriers that need to be overcome, such as the lack of continuous training for the teacher to use this resource and the lack of adequate infrastructure in schools. We intend, with this study, to collaborate with the debate about the use of technologies in Teaching History, its possibilities and challenges in the contemporaneity.

Keywords: History teaching; Pedagogical practice; Technology.

\section{Introdução}

Neste artigo, nos propomos analisar o uso das Tecnologias de Informação e Comunicação (Tic's) no Ensino de História, tendo em vista a forma como a disciplina se constituiu e a predominância, muitas vezes, de uma prática pedagógica convencional, o que causa desmotivação por parte dos alunos em estudar essa disciplina. Sendo assim, o uso das Tic's pode contribuir para o processo de ensino e aprendizagem, para a motivação dos discentes e a construção do conhecimento histório, levando-se em conta que os estudantes, na atualidade, tem contato com os mais diversos recursos tecnológicos. O que muitos professores têm buscado com a inserção das TIC's no universo escolar é minimizar o distanciamento existente entre as crianças e/ou jovens da nova era digital, chamados de nativos digitais (PRENSKI, 2001) e a escola como um todo.

Geralmente quando tratamos sobre a utilização de tecnologias, logo pensamos no seu uso como facilitadoras das tarefas cotidianas, para nos comunicarmos e nos relacionarmos com o mundo, para receber informações, estudar, entre tantas outras possibilidades. Mas quando pensamos na utilização das tecnologias no ambiente escolar percebemos ainda a grande dificuldade dos professores em fazer uso das TIC's na sua prática pedagógica. Isso se deve há diversos fatores como a falta de formação dos professores e a falta de infraestrutura das escolas.

Quando falamos em utilizar as tecnologias de forma eficaz, nos referimos não apenas na sua utilização, mas que as TIC's possam ser utilizadas como recurso agregador do processo de ensino aprendizagem e que amplie as condições para que os estudantes busquem o conhecimento. Sendo assim, apenas a utilização das tecnologias não significa qua vai ocorrer melhoria na aprendizagem, nem tão pouco que os alunos irão ficar mais motivados com a aula, pois

Para que as TIC's possam trazer alterações no processo educativo, no entanto, elas precisam ser compreendidas e incorporadas pedagogicamente. Isso significa que é preciso respeitar as especificidades do ensino e da própria tecnologia para poder garantir que seu uso, realmente, faça diferença. Não basta usar a televisão ou o computador, é preciso saber usar a forma pedagogicamente correta à tecnologia escolhida. (KENSKI, 2007, p.46) 
Em um momento em que o governo procura realizar investimentos para levar as tecnologias para dentro das escolas e a cobrança para que os professores façam uso desses recursos, também devemos pensar quais as reais condições são ofertadas ao professor para que ele possa, de fato, fazer um uso eficaz dessas tecnologias. Muitos projetos que prevêem a utilização de mídias em sala de aula fracassam devido à falta de conhecimento dos professores sobre como utilizar essas mídias de forma pedagógica. Preocupam-se em utilizar a tecnologia para ilustrar o conteúdo, mas não se preocupam com o contexto, com o interesse dos alunos e com a interação dos mesmos com a tecnologia utilizada.

Apresentados como soluções milagrosas para resolver os problemas educacionais, as tecnologias de informação e comunicação são utilizadas como estratégias econômicas e políticas por escolas e empresas, mas nem de longe, sozinhas, conseguem resolver os desafios educacionais existentes. (KENSKI, 2007, p.58)

Por outro lado, também é necessário que o governo invista na capacitação dos professores, pois muitos não sabem como utilizar as tecnologias no processo pedagógico. Embora o governo tenha implantado alguns programas e tenha feito certo investimento para equipar as escolas com salas de informática e outros aparatos tecnológicos, ainda há muito que fazer, tendo em vista que esses projetos não atendem todas as escolas. Além disso, não adianta haver tecnologia se os professores não forem capacitados para utilizá-la a favor do processo de ensino e aprendizagem, assim como não adianta ter sala de informática e outros equipamentos tecnológicos se não houver a manutenção dos mesmos, programas e softwares qualificados para o processo educativo.

Da mesma forma, Sibilia (2012) diz que embora haja a preocupação do governo em equipar as escolas com equipamentos como computadores e internet, deve-se ter a preocupação também com a manutenção dos equipamentos e atualização de hardwares e softwares. Além disso, deve-se questionar se essas tecnologias de fato integrarão um projeto inovador ou simplesmente comporão o cenário da escola sem efetiva função pedagógica.

É realmente um desafio para todos os educadores, mas em relação aos professores do ensino de História, foco desse artigo, acreditamos que as novas tecnologias possam auxiliar na formação da consciência histórica dos alunos, bem como potencializar a compreensão dos estudantes sobre a responsabilidade em fazer parte da história do presente, pois como diz Moran:

A educação tem de surpreender, cativar, conquistar os estudantes a todo o momento. A educação precisa encantar, entusiasmar, seduzir, apontar possibilidades e realizar novos conhecimentos e práticas. O conhecimento se constrói com base em constantes desafios, atividades significativas que excitem a curiosidade, a imaginação e a criatividade.(MORAN, 2009, p.167) 
Guimarães (2015) relata que desde a segunda década do século XX é possível perceber no Brasil a ampliação do acesso as tecnologias, apesar das discrepâncias sociais, culturais e econômicas “as TDIC's passaram, pois, a fazer parte da agenda de lutas dos jovens que as reinvindicam fora e dentro do espaço escolar” (GUIMARÃES, 2015, p.365). Portanto, apesar de uma parte considerável das crianças e adolescentes, devido a condições econômicas, estarem fora do universo digital, há aquelas que estão muito bem adaptadas as mais variadas tecnologias, pois já nasceram e cresceram em meio aos mais diversos artefatos digitais e solicitam uma mudança na prática dos professores e da escola. Uma prática conectada com a sociedade tecnológica atual e dentro deste contexto é necessário repensar a escola a fim de fazer com que nossos estudantes vejam sentido no espaço escolar e sintam-se envolvidos e responsáveis pelo seu processo de aprendizagem, que sintam-se motivados, que desejem estar na escola e buscar o conhecimento.

No que tange o ensino de história, as TIC's podem ser utilizadas a fim de proporcionar um ensino que dialogue de forma ativa com os estudantes, já que neste campo do conhecimento nota-se a predominância de um ensino tradicional, com base na memorização e na valorização de grandes acontecimentos, dos heróis e datas. Muitos professores neste campo vêem os estudantes como sujeitos passivos, que devem repetir nas avaliações o que lhe foi transmitido. Por vezes, o ensino de história não faz sentido para os discentes, que não percebem o contexto do que estão aprendendo, da sua importância para a compreensão do presente e do ser histórico que todos somos. Sendo assim, as tecnologias quando bem utilizadas podem contribuir com diversas disciplinas e no caso do ensino de história podem ser um potente mecanismo de envolvimento dos discentes.

\section{O Ensino de História: uma breve revisão}

Após a Independência do Brasil (1822), surgiram projetos a fim de organizar os currículos de História, considerando as demandas do novo Estado que surgia. De acordo com Fonseca (2011) é após a independência que a História ganha status de disciplina, com metodologia específica e conjunto de saberes reconhecidos no campo científico. Nas décadas de 20 e 30 do século XX ocorrem debates em torno de projetos para a educação e como seria organizado cada disciplina, dentre elas a disciplina de História. Fonseca (2011) destaca que a consolidação da História como disciplina escolar ocorre nas reformas de ensino durante as décadas de 30 e 40, quando a História se tornou centro das propostas de formação da Unidade Nacional. Já durante o Regime Militar, instalado no Brasil em $1^{\circ}$ de abril de 1964, durando até 
março de 1985 quando o país foi governado por militares, o ensino de História foi reorganizado a fim de adequar a ordem vigente, sendo adotadas medidas restritivas tanto na formação quanto na atuação dos professores para que não houvesse nenhuma forma de resistência ao regime. Na década de 1980, após a ditadura militar, surgiram diversos debates para readequação do currículo de História onde:

[...] o grande marco dessas reformulações concentrou-se na perspectiva de recolocar professores e alunos como sujeitos da História e da produção do conhecimento histórico, enfrentando a forma tradicional de ensino trabalhada na maioria das escolas brasileiras, a qual era centrada na figura do professor como transmissor e na do aluno como receptor passivo do conhecimento histórico. (SCHIMIDT, CAINELLI, 2009, p. $14)$.

Já na década de 90 surge a ideia de uma abordagem em comum para o currículo de história. Em 1996 ocorre a criação da Lei de Diretrizes e Bases da Educação (LDB- Lei no 9394/96), estabelecendo as diretrizes e bases da educação nacional e prevê, dentre outras questões, que o ensino da História do Brasil deva considerar as diferentes culturas e etnias que contribuíram para a formação do povo brasileiro, como os indígenas, os africanos e os europeus. Entre os anos de 1997 e 1998, foram publicados pelo Ministério da Educação, os PCN’s (Parâmetros Curriculares Nacionais), com objetivo de estabelecer temas comuns aos currículos, servindo de eixo norteador para as escolas de forma geral. Já em 2008 foi publicada a Lei $\mathrm{n}^{\circ} 11.645$, de 10 de março que estabelece a obrigatoriedade do estudo da cultura afro-brasileira e indígena na escola. O artigo $26 \S 10$ diz que

O conteúdo programático a que se refere este artigo incluirá diversos aspectos da história e da cultura que caracterizam a formação da população brasileira, a partir desses dois grupos étnicos, tais como o estudo da história da África e dos africanos, a luta dos negros e dos povos indígenas no Brasil, a cultura negra e indígena brasileira e o negro e o índio na formação da sociedade nacional, resgatando as suas contribuições nas áreas social, econômica e política, pertinentes à história do Brasil. (BRASIL, 2008)

Sendo assim, procuramos avaliar as principais mudanças que ocorreram em relação ao ensino de História no Brasil desde sua constituição como disciplina escolar até os tempos atuais. Essa análise é relevante, pois compreender a constituição histórica desta disciplina possibilita entender porquê muitos professores ainda estão atrelados à uma prática convencional que prioriza o livro didático como principal recurso pedagógico, a transmissão de conhecimento, a história cronológica, linear e factual, sem preocupação com a produção do conhecimento.

De acordo com Fonseca (2011) as disciplinas escolares foram sendo organizadas de acordo com o interesse de grupos e instituições. As primeiras disciplinas escolares foram 
organizadas na Idade Média e já apresentavam como característica a ideia de adquirir conhecimento sobre uma área específica. A História, enquanto campo de conhecimento foi se modificando de acordo com o debate científico e com as ciências humanas. "A rigor, somente a partir do século XVIII é que a História começou a adquirir contornos mais precisos, como um saber objetivamente elaborado e teoricamente fundamentado" (FONSECA, 2011, p.21). Da Idade Média ao século XII, tem-se o predomínio religioso, onde a história humana dava-se pelo divino, a formação dos Estados Nacionais desvia o foco do religioso para o político e o discurso historiográfico deixa de lado a genealogia eclesiástica para se fixar na genealogia das dinastias e de nações, traço que se manteve até o início do século XX.

Fonseca (2011) diz que o caminho do ensino de História nas escolas não foi o mesmo da história como campo do conhecimento e que os conteúdos a serem ensinados se tornaram importantes na Idade Moderna a fim de formar a elite, principalmente os príncipes. Desde o fim do Antigo Regime a história ensinada mesmo não sendo constituída como disciplina, era aquela que ensinava a origem das Nações. A autora diz ainda que durante a Revolução Francesa, a educação foi assunto de grande importância, mas a História continuou sendo uma disciplina secundária, servindo para que se refletisse sobre "as civilizações e sobre o progresso da humanidade" (FONSECA, 2011, p. 23). No início do século XIX em vários países da Europa, a educação passou a ser de responsabilidade do Estado que se preocupava com a formação dos sujeitos, com a manutenção do sistema capitalista e com o fortalecimento do nacionalismo. Nesse período a "Historia, como campo de conhecimento, começou a apresentar maior sistematização em termos de investigação e de seus métodos, procurando o equilíbrio entre as dimensões erudita e filosófica" (FONSECA, 2011, p.24).

Enquanto disciplina que servia ao Estado, a História acabou se tornando importante instrumento para legitimar o poder político e afirmar a identidade nacional, já que ela apresentava as glórias da Nação e os feitos dos grandes heróis. Isso ocorreu tanto na Europa como na América.

\subsection{O Ensino de História no Brasil: do Império à Ditadura Militar}

Surgida como disciplina em nosso país no período imperial, a história tinha como base o modelo francês e privilegiava os "grandes feitos" e as figuras dos "heróis". O Colégio D. Pedro II, primeiro colégio de ensino secundário do país, foi o primeiro a introduzir a história como disciplina a partir de 1838. Segundo Fonseca (1994, p.49), “o ensino de História na escola fundamental brasileira, esteve, desde sua inclusão nos programas escolares (século XIX), fortemente e articulado as tradições européias, sobretudo francesa”. Do século XIX ao 
início do XX, se privilegiava a história universal, dividida em história antiga, média, moderna e contemporânea, onde a história do Brasil era estudada junto à história universal, sendo considerado o estudo da história do país com pouca importância, já que se privilegiava a história universal, sobretudo a européia. Ainda segundo Fonseca (1994, p.51) “o eurocentrismo foi aplicado de forma marcante não só nos programas de ensino, mas também na pesquisa histórica e na organização dos currículos dos cursos superiores em história".

Fonseca (2011) diz que em 1838 foi criado o IHGB (Instituto Histórico e Geográfico Brasileiro) e este deveria elaborar a história do Brasil a ser ensinada nas escolas através da disciplina de história por meio de manuais didáticos. Assim, foram unificados objetivos da igreja e do Estado na medida em que a história deveria formar moralmente crianças pelos princípios cristãos da fé católica e também porque deveria ensinar grandes acontecimentos da história do Império. Em todo o século XIX ocorrem discussões e mudanças nos programas escolares e o objetivo do ensino de história vai aos poucos se definindo. "produzia-se e ensinava-se, a julgar pelos programas e pelos textos dos livros didáticos, uma história eminentemente política, nacionalista e que exaltava a colonização portuguesa, a ação missionária da Igreja Católica e a monarquia” (FONSECA, 2011, p.47)

Sendo assim, os conteúdos a serem trabalhados no ensino de História e os planos de estudos só se concretizaram com a criação, em 1837 do colégio D. Pedro II, que introduziu a disciplina de História no ano seguinte. O colégio vai servir como modelo para as escolas do Império, bem como a forma de organizar o currículo de História, com base no modelo francês, onde mesmo a História Universal tendo predominância no currículo, ainda tinha fortes bases da História Sagrada, com vistas à educação moral e religiosa.

Com o surgimento da República (1889) surge a preocupação com os métodos e recursos utilizados no ensino de História, principalmente nas décadas de 30 e 40, quando a História se torna centro das propostas de formação da unidade nacional. Em 1931 é criado o Ministério da Educação e Saúde, que ficaria encarregado de elaborar os programas curriculares. Na Reforma do Ensino de Francisco Campos (1931) o ensino secundário tornase obrigatório e a disciplina ganha mais espaço. Já na Reforma de Gustavo Capanema (1942) as orientações para o ensino de História consolidam a divisão quadripartite da História universal. O modelo quadripartite francês, dividiu o Ensino de História em: Idade Antiga, Idade Média, Idade Moderna e Idade Contempórânea e serviu de base para as escolas brasileiras. A História do Brasil passou a ser estudada em dois módulos: um até a independência e o outro a partir desta. No Decreto-Lei no 4.244 de 9 de abril de 1942, ficava estabelecido que o ensino secundário seria estruturado em Curso Ginasial, Clássicos e 
Científicos e que os mesmos deveriam contemplar as disciplinas de História Geral e História do Brasil. Também caberia a História do Brasil, associado a disciplina de Geografia do Brasil, nos estudos clássicos e científicos, o estudo dos problemas vitais do país, bem como primar pela formação de uma consciência patriótica. Ou seja, tanto os programas curriculares quanto as orientações metodológicas traçavam-se, pela ideia de construção nacional que, "a partir das noções de pátria, tradição, família e nação, formaria na população o espírito do patriotismo e da participação consciente" (Fonseca, 2011, p.54)

A partir da segunda guerra mundial (1939-1945) ocorre uma mudança na forma de ver a História, já que a Europa não era mais a soberana no mundo. Os historiadores passaram a buscar conhecimento e construir seus objetos de investigação, deixam de aceitar que os fatos falem por si só e buscam a compreensão dos acontecimentos de uma forma mais ampla. Cabe destacar a entrada de outro paradigma no campo historiográfico, vinculado a Nova História, que passou a valorizar a história do cotidiano em preterimento a história dos heróis. Segundo Le Goff (1990) a fundação da revista dos Annales foi o que tornou possível o nascimento da Nova História. Surgida na França, na primeira metade do século XX, a Escola dos Annales foi um movimento historiográfico que renovou a historiografia tentando romper com a historiografia tradicional, apresentando novos elementos para o conhecimento das sociedades. Seus principais contribuidores Marc Bloch e Lucien Febvre propunham que a historiográfica privilegiasse o econômico e o social ao invés do político.

De acordo com Samara e Tupy (2010), antes da segunda metade do século XX, os historiadores utilizavam em suas pesquisas os documentos ditos "oficiais" como cartas, relatórios, atas, etc, contribuindo para que fosse construída uma história política. Porém, a partir desse período, sob a influência da Escola dos Annales, outros tipos de documentos passaram a ser utilizados, além de outras formas de duração-periodização. Ainda segundo as autoras, na última década tem ocorrido uma reflexão em relação aos métodos e técnicas de trabalho, principalmente porque a tecnologia tornou possível a digitalização de documentos, criação de banco de dados, além de acelerar a troca de informações, fazendo com que haja mudanças nas práticas de pesquisa.

A História atualmente considera como fonte diversos registros, sejam escritos ou não. O uso das tecnologias tem possibilitado novos métodos e técnicas de trabalho e os historiadores tem acesso a uma série de documentos contidos em diversos bancos de dados do mundo. Além disso, novos temas são abordados, novos olhares sobre temas antes pesquisados, fazendo com que a História reafirme seu dinamismo enquanto ciência. Porém, apesar dessas mudanças que ocorreram no campo da pesquisa historiográfica, a história 
ensinada nas escolas ainda carrega muito de sua base tradicional, prevalecendo os grandes feitos, grandes heróis, datas, memorização e repetição.

No Brasil, a História se constituiu dentro dos currículos escolares e nas produções didáticas como uma disciplina que pretendia explicar a sociedade brasileira. De acordo com Pinsky (1994), a partir dos anos 40 e principalmente nos 50 do século XX, ocorre uma maior popularização da escola e embora o acesso tenha sido estimulado, nota-se um grande índice de evasão e desistência. A população de menor poder aquisitivo não conseguia freqüentar a escola, por diversos motivos, dentre eles a necessidade de ingressar no mercado de trabalho. Segundo Pinsky (1994, p.25) os índios, europeus e escravos africanos formam a base da nossa sociedade e a disciplina de História cumpre a função de criar um passado harmônico que camufla as nossas diferenças, o passado aparece, portanto, de maneira a homogeneizar e a unificar as ações humanas na constituição de uma cultura.

Assim como as transformações econômicas e sociais refletiram na educação brasileira, também influenciaram o ensino de História. Estivemos atrelados durante longo período a história tradicional a partir de uma perspectiva positivista, onde o que interessava eram os fatos históricos, comprovados através dos documentos escritos, cabendo ao professor transmitir os acontecimentos e aos alunos a memorização dos mesmos. O positivismo foi uma corrente de pensamento surgida na primeira metade do século XIX, tendo em August Comte seu idealizador, que acreditava que uma teoria só seria válida se fosse comprovada. A História, portanto, enquanto ciência deveria ser explicada através do que pudesse ser comprovado através de documentos, delineando-se uma história dada de forma linear, ressaltando os grandes acontecimentos e heróis da pátria.

Podemos perceber claramente a presença dessa concepção de História no estudo de Cruz (2001), que realizou uma pesquisa com alunos de pós graduação em Educação, de diferentes áreas do conhecimento, e investigou como os mesmos definiam a História. O autor conclui que os pesquisados definiram a História como

Uma concepção positivista da História, caracterizada pela ideia de um conhecimento absoluto, definitivo, pois comprovado pelos "fatos". Transformações que ocorrem de maneira mecânica, num encadeamento de causa e consequências. A História como um conhecimento global, organizando todo o passado da humanidade, num continuum harmonioso, que sofre as transformações em conjunto, como se a humanidade se constituísse num todo que evolui a partir de causas e consequências comuns. Enfim, há um conhecimento pronto, acabado, não passível, por tanto, de questionamento. (CRUZ, 2001 p.67) 
A partir da segunda metade do século XX, sob influência da Escola dos Analles o fazer histórico passou a valorizar mais o social, dando importância ao estudo do cotidiano. Além de se preocupar com os homens comuns, a mentalidade coletiva também passou a considerar como fonte histórica qualquer vestígio deixado pelo homem, ainda assim, a disciplina passa por momentos difíceis como no período da ditadura militar (1964-1985), em que foi praticamente suprimida ao ser unificada com a disciplina de geografia e sua transformação em Estudos Sociais.

\subsection{O Ensino de Históra no Período Militar}

O governo militar teve início no Brasil em 1964, permanecendo até o ano de 1985. Nesse período, os professores deveriam seguir o currículo estabelecido pelo Estado, sem refletir de forma crítica sobre aquilo que se passava na sociedade brasileira, pois os espaços educativos eram rigorosamente monitorados. Nesta lógica, para atender os interesses do Estado, o professor de História foi “desqualificado" para não subverter a ordem de um Estado que se mostrava antidemocrático. Isso porque os professores de História eram vistos como pessoas que estimulavam o censo crítico e que poderiam atuar sobre seus alunos de maneira oposta a desejada pelo regime, sendo assim, muitos professores desta disciplina foram perseguidos pelo governo, além de terem limitadas sua atuação em sala de aula.

[...] desqualificar o professor de História, ou qualificá-lo e prepará-lo para uma escola que impunha tarefas e necessidades de submissão da maioria da sociedade brasileira, significava, sem dúvida, fortalecer e legitimar um modelo antidemocrático e concentrador de riquezas, além de limitar ainda mais as possibilidades de debates mais profundos (na área) no interior das nossas escolas de $1^{\circ}$ e $2^{\circ}$ graus. (FONSECA, 1994, p.29).

Percebe-se claramente através do Ato complementar 75 de $1969^{3}$ como ele ameaçava os professores e cientistas, pois a partir dele, o governo controlava a produção científica, o que causou temor nas universidades. Diz o Ato em seu artigo $1^{\circ}$ que:

Todos aqueles que, como professor, funcionário ou empregado de estabelecimento de ensino público, incorreram ou venham a incorrer em faltas que resultaram ou venham a resultar em sansões com fundamento em Atos Institucionais, ficam proibidos de exercer, a qualquer título, cargo, função, emprego ou atividades, em estabelecimentos de ensino e em fundações criadas ou subvencionadas pelos Poderes Públicos, tanto da União, como dos Estados, Distrito Federal, Territórios e Municípios, bem como em instituições de ensino ou pesquisa e organizações de interesse da segurança nacional. (ATO COMPLEMENTAR $\mathrm{n}^{\circ} 75$, de 20 de outubro de 1969).

De acordo com Fonseca (1994), na década de 70 era privilégio das universidades a busca e produção do conhecimento histórico enquanto as escolas de $1^{\circ}$ e $2^{\circ}$ graus deveriam

\footnotetext{
${ }^{3}$ Texto disponível em http://www.planalto.gov.br/ccivil_03/ACP/acp-75-69.htm. Acesso em 16/11/2017
} 
ensinar os saberes já consolidados. Os alunos destes níveis eram pouco estimulados a produzir conhecimento e o professor pouco valorizado, pois devia se restringir a ensinar seguindo o livro didático. A mesma autora afirma que a escola estava inserida dentro do processo capitalista, atendendo aos interesses do Estado, que controla a produção do conhecimento. A indústria cultural foi incentivada no governo militar, beneficiando principalmente empresas estrangeiras, com o estímulo a indústrias editoriais através de incentivos fiscais e subsídios. Esse mercado editorial, em franca expansão gerou disputas entre EUA e França, especialmente disputas em torno do "livro didático que se torna uma das mercadorias mais vendidas da indústria editorial" (FONSECA, 1994, p. 138). Essa indústria cultural atendia as necessidades do Estado e de seu projeto de segurança nacional, além de beneficiar aos interesses das multinacionais.

[...] o consumo em massa de livros didáticos de História, socializando certo saber histórico, não contribuiu para o desenvolvimento da compreensão da História de forma crítica entre nossos alunos. O livro didático de História, em sintonia com os currículos da década de 70, tornou-se o canal privilegiado para a difusão e imposição de uma história excludente, reprodutora por excelência da memória oficial da nação. (FONSECA, 1994, p. 141)

Ainda de acordo com Pinsky (1994, p. 18) no final dos anos 50 e início dos 60 sentiuse a necessidade de mudanças e de organizar estudos sobre a realidade brasileira, onde autores clássicos como Caio Prado Júnior, Karl Marx e Celso Furtado eram lidos em grupos de estudo para tentar compreender o ser histórico. Porém, após o quinto ano do governo militar essas reflexões foram restringidas, pois bastava, na visão do governo os estudantes decorarem os nomes dos grandes heróis, datas e acontecimentos. Nesse contexto, ao aluno não cabia uma postura reflexiva ou crítica, mas sim uma postura passiva e repetitiva ao que lhe era transmitido. A História não devia formar o sujeito histórico crítico e consciente, capaz de refletir sobre o mundo e os acontecimentos históricos, mas devia formar um ser alienado, incapaz de relacionar o conhecimento à sua realidade. Segundo o autor, essa intenção encontrou alguns obstáculos como as péssimas condições de trabalho dos professores, baixos salários e excessiva carga horária; tais condições ainda vistas na atualidade.

Através da lei 5.692 de 11 de agosto de 1971, pela Resolução ${ }^{\circ} 8$, anexa ao parecer $\mathrm{n}^{\circ}$ $853^{4}$, a disciplina de História é suprimida, passando a fazer parte, combinado à disciplina de geografia e de Organização Social e Política do País, em uma nova disciplina denominada de

\footnotetext{
${ }^{4}$ Texto encontrado em http://www.scielo.br/pdf/reben/v25n1-2/0034-7167-reben-25-02-0176.pdf, Acesso em $12 / 11 / 2017$
} 
Estudos Sociais. Segundo Fonseca (2011, p. 58) os Estudos Sociais tinham como finalidade básica "ajustar o aluno a seu meio, preparando para a convivência cooperativa e para suas futuras responsabilidades como cidadão, no sentido do cumprimento dos deveres básicos para a comunidade, o Estado e a Nação".

Fonseca (1994), relata sobre a proposta do governo militar com o Mobral e o projeto profissionalizante colocando que, mesmo havendo um grande salto no número de matrículas nas décadas de 70 e 80 , tanto no $1^{\circ}$ grau, como em cursos de graduação e pós-graduação, a formação geral perdeu espaço para a formação tecnicista, pois se priorizou a formação para o trabalho em detrimento da formação humana, social, política e cultural. Não era interesse para aquele governo ditatorial que os cidadãos se tornassem conscientes e críticos. Somente com o fim do regime militar, algumas disciplinas da área de humanas ressurgiram nos currículos escolares como a história e a geografia, embora ainda de forma tímida, com carga horária reduzida se comparada com as ciências exatas.

A mesma autora ainda diz que a portaria $\mathrm{n}^{\circ} 790$ de 1976, definia que somente os professores com formação em Estudos Sociais poderiam ministrar essa disciplina e relegava aos professores de História e geografia as poucas aulas nas escolas de $2^{\circ}$ grau, o que de certa forma, marginalizou esses profissionais, pois ficavam com um espaço de trabalho limitado. A autora afirma que além da questão econômica, o interesse do Estado era formar jovens para o mercado de trabalho, sem potencializar o pensamento crítico e autônomo. As licenciaturas curtas se encaixavam na proposta do governo, pois os futuros professores recebiam uma formação acelerada que priorizava os conhecimentos específicos e práticos. Fonseca (2011) também nos relata que durante esse período, os fatos históricos eram vistos de forma linear, onde o professor está no centro do poder/saber e o livro didático é sua principal ferramenta no ensino. Nesse contexto, não cabe ao aluno uma reflexão ou critica, mas cabe a ele ser passivo e receptivo ao que lhe era transmitido. A Historia geral estava baseada no modelo quadripartite e a História do Brasil dividida entre os períodos da Colônia, Império e República, vistas de forma cronológica e com marcos divisórios como eventos significativos da historia política. As características do ensino desse período, ainda são evidentes, tanto através dos livros didáticos que mantém a mesma periodização, como nos programas curriculares e práticas docentes.

Ainda assim, apesar da repressão, o ensino de História passa a ser repensado e vai ganhando espaço em associações científicas e sindicais como: ANPUH, SBPC, APEOESP-SP e UTE-MG. As associações científicas e sindicais estimularam a revisão legal sobre a função 
do professor de História, bem como potencializam o debate sobre a cientificidade da História no campo das ciências humanas.

Outro autor diz que:

[...]as mudanças ocorridas no ensino de história nas décadas de 70 e 80 situam-se no movimento historiográfico vivido no Brasil, nas modificações ocorridas no debate acadêmico, no mercado editorial, na pós-graduação, enfim, na produção histórica. (FONSECA, 1994.p. 111)

[...]a generalização de uma preocupação crítica com a história deve ser datada dos anos setenta, quando as gerações saídas das universidades anos antes começam a encontrar legitimidade intelectual e ensaiam um ensino mais preocupado com o social. (PINSKY, 1994, p. 19)

Percebemos, através da visão dos autores citados acima que, mesmo com a repressão do regime militar, especialmente no fim da década de 70 e início de 80 , os professores de História, através de lutas e de suas entidades representativas, conquistam um espaço, trabalhando na perspectiva humanista, de formar cidadãos críticos e conscientes da sua importância como sujeitos históricos.

\subsection{O Ensino de História: do fim da ditadura aos dias atuais}

Segundo Fonseca (2011), com o fim do regime militar e a redemocratização, surgem novos debates em torno do ensino de história, especialmente no início dos anos 80. Como exemplo, o estado de São Paulo discute as propostas para a reformulação da disciplina no estado, envolvendo professores, indústria editorial, secretaria de educação e imprensa. A proposta era um ensino voltado a potencialização do cidadão que, embora interessante, demorou cinco anos para ser implantada. Já em Minas Gerais os livros didáticos do ensino fundamental foram reorganizados de forma a integrar a História Geral e História do Brasil, de forma cronológica, tal iniciativa significava uma organização curricular nova para o ensino de História, “o programa curricular implantado em Minas Gerais, em 1986, foi considerado, por muitos, como síntese das expectativas de um ensino de História democrático e participativo, e que refletia o momento político vivido até então" (FONSECA, 2011, p.61).

Fonseca (2011) relata ainda que as discussões em torno das propostas levaram a buscar uma História enquanto ciência que precisava de um novo método de ensino e novos conteúdos, não baseada na linearidade, nos grandes feitos, no factual

o programa de 1986 pretendia que houvesse uma prática totalmente inovadora e diferenciada por parte dos professores e alunos, por meio de uma mudança de pontos de referência, de visão do processo histórico que, deixando de privilegiar os grandes fatos políticos e os grandes personagens da história oficial, partiriam das lutas de 
classes e das transformações infraestruturais para explicar a história, revelando, assim, sua clara fundamentação no marxismo. (FONSECA, 2011, p. 63)

Assim a proposta implementada em Minas Gerais ganhou simpatia de todo o Brasil num momento de luta contra o autoritarismo. Aproveitando-se das mudanças curriculares, o mercado editorial cria novas coleções. A História a ser ensinada era apoiada no materialismo histórico, mas em fins dos anos 80 e início dos 90 há uma renovação sob a influência da Nova História. A disciplina manteve suas características desde sua constituição no século XIX, mas com a preocupação em interligar o saber científico e o escolar, onde "para muitos, a qualidade do ensino de História ministrado nas escolas estaria diretamente relacionada à capacidade desta disciplina em levar para o ensino fundamental e médio as discussões historiográficas mais recentes em curso no Brasil" (FONSECA, 2011, p.66). Ainda de acordo com a autora, apesar das reformas ocorridas especialmente após o Regime Militar, não houve abalo em relação à concepção do ensino dessa disciplina, que teve seu alicerce construído desde o fim do século XIX sob uma ótica tradicional. Embora a disciplina não seja mais a mesma desde sua constituição, ainda guarda elementos de sua origem.

Para Gimarães (2015), a partir de 1990 alguns resultados foram obtidos através da lutas em torno de uma nova política educacional, como a consolidação do ensino de História e de Geografica como disciplinas autônomas e independentes (unificadas sob a disciplina de Estudos Sociais no governo militar), a aprovação da Lei de Diretrizes e Bases da Educação Nacional (LDB, Lei no 9394/96)), os PCN's (1997), entre outros. Diz que na passagem dos anos 1990 e 2000, Novas Diretrizes Nacionais foram implantadas em relação aos cursos superiores de História e a formação de professores da educação básica. Temos a criação da lei 10.639/03 que tornou obrigratório o estudo da História e Cultura Afro-brasileira e a criação da lei 11.645/08 que torna obrigatório o estudo sobre a temática indigena. Temos o crescimento de cursos a distância para formação de professores, especialmente através do desevolvimento e ampliação do acesso às TIC's, aumento de produções científicas sobre o ensino de história, principalmente através do crescimento dos grupos de pesquisas e de pesquisadores das universidades, além da consolidadação dos eventos acadêmicos de forma periódica como espaço de formação de professores e pesquisadores. Para essa autora,

discutir o Ensino de Historia, no séxulo XXI, é pensar os processos formativos que se desenvolvem em diversos espaços e as relações entre sujeitos, saberes e práticas. Enfim, é refletir sobre o modos de educar cidadãos numa sociedade complexa, marcada por diferenças e desigualdades." (GUIMARÃES, 2015, p. 20) 
A disciplina de História deve formar cidadãos críticos e ativos na sociedade e, sendo assim, muitos professores estão buscando alternativas e pensam suas práticas pedagógicas como espaço de interação e construção do conhecimento com o estudante. Nesse sentido, as tecnologias podem ser fortes aliadas para que o ensino se renove, tornando as aulas motivadoras. Segundo Karnal (2010) após o surgimento das tecnologias os livros passaram a ser considerados desinteressantes e os alunos preferem pegar informações em qualquer site a consultar um livro e fazer uma investigação bibliográfica. Diz ainda que o ensino de História é importante na formação humanista e que o professor de História deve ter consciência que ele tem responsabilidade social para com os alunos. Ainda assim, considerando-se a potencialidade das TIC's, "uma aula pode ser muito dinâmica e inovadora utilizando giz, professor e aluno". Podemos utilizar meio novos, mas é a própria concepção de História que deve ser repensada" (Karnal, 2010, p. 9).

\subsection{O que dizem as pesquisas sobre o tema}

Realizando o levantamento sobre o uso das Tic's no Ensino de História, percebemos que ainda há poucos trabalhos nesse campo do saber. Selecionamos 13 dissertações de mestrado, que tratam do ensino de História e o uso das Tics de forma dialogada, para identificarmos como se dá a utilização das tecnologias no ensino dessa disciplina.

Após a realização das leituras e análise das mesmas, percebemos pontos em comum em relação aos trabalhos apresentados. A exemplo, quanto ao ensino de História, alguns pesquisadores dizem perceber a desmotivação dos alunos em relação às aulas, o que os motivou a procurar inserir as tecnologias na sua prática pedagógica, tendo em vista a percepção da motivação dos alunos para com aulas que envolvem as tecnologias como por exemplo os trabalhos de Caramez (2014), Cruz (2013), Tavares (2015) e Timóteo (2012), Algumas pesquisas tratam da falta de formação dos professores para lidar com as tecnologias como instrumento pedagógico, pois os professores não sentem-se preparados para incorporar as Tic's a suas aulas. Encontramos essa afirmação anterior nos trabalhos de Araújo (2017), Fernandes (2012), Guimarães (2013), Tomaz (2005) e Timóteo (2012). Além da falta de formação dos professores, alguns pesquisadores como Araújo (2017), Cruz (2013), Fernandes (2012) Gonçalves (2015), Vasconcelos Júnior (2009), Rodrigues (2016) Tomaz (2005) e Timóteo (2012) relatam a falta de estrutura das escolas, a carência de laboratórios de informática e outros aparatos tecnológicos, além da falta de manutenção dos mesmos e dificuldades de acesso à Internet, o que dificulta possíveis trabalhos a serem realizados pelos professores envolvendo essas tecnologias. Alguns dos pesquisadores relataram que uma das 
motivações para a realização da pesquisa é a falta de trabalho nesse campo como Caramez (2014), Cruz (2013), Leivas (2004) e Tavares (2015).

Todas as pesquisas lidas tratam das possibilidades do uso das Tic's nas aulas de História, a fim de motivar os alunos e romper com a aula convencional, desde que haja um planejamento por parte do professor e que as mesmas sejam utilizadas de forma diferenciada, ou seja, proporcionar aos alunos a aproximação com a realidade, rompendo com a aula convencional onde predominam os grandes fatos, os grandes heróis, com acontecimentos dados de forma linear e não passíveis de questionamentos. Isso porque parte dos pesquisadores como Gonçalves (2015), Guimarães (2013), Vasconcelos Júnior (2009) e Tomaz (2005), percebem que ainda hoje predomina esse ensino convencional, com base na repetição e memorização de uma história factual e linear, mesmo entre aqueles professores que utilizam as tecnologias em suas aulas.

Para melhor análise das pesquisas selecionadas, procuramos dialogar com aquelas que tratam de temas em comum. A exemplo de Araújo (2017), Cruz (2013) e Guimarães (2013), que abordam em seus trabalhos o uso do computador e da internet. Ambos os pesquisadores acreditam na potencialidade do uso do computador e da internet na prática pedagógica, desde que seja utilizado de forma planejada e eficaz. Apesar disso, suas pesquisas constataram a falta de formação dos professores para lidarem com essas tecnologias de forma significativa, bem como a falta de estrutura das escolas. A exemplo, Guimarães (2013) diz que o professor não é formado adequadamente para lidar com as tecnologias, causando insegurança aos mesmos em utilizá-las. Cruz (2013) relata que há muitos problemas como o despreparo do professor, dificuldades de acesso à internet, falta de manutenção nos equipamentos, entre outros. Assim, acredita que a escola não está preparada para trabalhar com projetos, que se utilizem da tecnologia e propor mudanças na forma de ensinar. Para Cruz (2013) o desafio atualmente é fazer com que o computador e a internet sejam integrados a prática curricular no cotidiano da escola. Já Araújo (2017), diz que é preciso preparar os professores para lidar com essas tecnologias e que muitos professores relutam, pois não se sentem qualificados, além da falta de estrutura presente nas escolas, falta de motivação e muitas vezes desinteresse.

O que chamou atenção dentre os trabalhos analisados é a predominância da forma convencional do ensino de história, ainda focado no conteúdo dado de forma factual e linear, sem contextualização e distante da realidade dos alunos, o que causa desinteresse dos mesmos pela disciplina. Mesmo com o uso das tecnologias, apesar da motivação dos alunos para com as aulas, as mesmas acabam por não contribuir para uma aprendizagem significativa. Pode-se constatar esse dado através da pesquisa de Guimarães (2013), que após observar as aulas de 
uma professora que utilizou lap tops em suas aulas, percebeu que nada mudou na prática da professora em relação ao ensino convencional, pois a organização da sala continuou a mesma, com as cadeiras enfileiradas, bem como a forma da professora ministrar a aula. Diz que mesmo a professora tendo a preocupação no planejamento das aulas, as aulas foram ministradas com o ensino centrado na figura do professor onde segundo a pesquisadora isso pode ser justificado pela falta de formação da professora em utilizar as tecnologias de forma pedagógica.

Dentro dessa perspectiva, Gonçalves (2015) em sua pesquisa concluiu que apesar de estarmos rodeados pelas tecnologias e de os professores fazerem uso das mesmas no seu cotidiano e de reconhecerem sua importância para a aprendizagem, por muitas vezes não às utilizam como recurso a favor da aprendizagem dos alunos, pois em muitos casos ministram suas aulas de forma tradicional onde o professor é o centro do processo de aprendizagem, desconsiderando o estudante como sujeito ativo neste processo. Gonçalves (2015) ainda diz que que os professores alegam utilizar uma forma tradicional de ensino porque assim aprenderam na universidade e observam a cobrança do governo em relação aos conteúdos que devem ser ministrados e as provas que são realizadas, como exemplo o Enem, que valoriza a memorização. A autora ainda conclui que embora os professores considerem importante a inserção das TIC's eles a usam como substituição de sua fala, para facilitar sua prática e não como algo a mais para a aprendizagem.

Vasconcelos Júnior (2009) buscou analisar em sua pesquisa se os softwares educacionais para o uso na disciplina de Hhistória modificam a prática convencional. O que ele constata é que os softwares analisados, apesar de apresentarem bons recursos iconográficos, se preocupam mais com os conteúdos, ressaltando os grandes acontecimentos, datas e figuras de heróis e pouco se preocupam com exercícios onde os alunos possam demonstrar a aprendizagem. Conclui que embora sejam divulgados como inovadores, no fundo se mostram com a mesma tendência tradicional, valorizando a memorização e utilizando a repetição como estratégia de fixação, não se constituindo como instrumentos realmente inovadores, pois são apenas uma nova roupagem para apresentar o mesmo conteúdo e desenvolver a mesma aptidão.

Outro pesquisador que também analisa o uso dos softwares educacionais é Tomaz (2005), ele apresenta uma visão diferente, não encontrando problemas em relação aos softwares que foram analisados, a exceção da ausência de fontes nas imagens, ele relata a potencialidade desses recursos e destaca que o mais importante não é o recurso, mas a utilização que o professor fará do mesmo. Segundo ele, ainda hoje vemos muitas práticas 
onde o professor é o centro do conhecimento, com aulas baseadas em manuais didáticos, sem levar em conta a situação e experiência de cada aluno.

Peres (2016) ao analisar o livro-aplicativo, concluiu que esse recurso ainda aborda uma história com os conteúdos apresentados de forma factual, não permitindo o desenvolvimento de uma consciência histórica. Segundo o autor, o livro aplicativo trouxe um avanço em relação à duração e permanência do tempo, com a ideia de se compreender o tempo histórico e a simultaneidade que ainda é tão pouco trabalhado nas escolas. Ainda assim é um avanço parcial, pois a interface do aplicativo limita o trabalho em alguns momentos. Algumas das pesquisas analisadas relatam que é possível romper com a aula tradicional, tornando-as mais motivadoras e produtivas. É o caso da pesquisadora Tavares (2015), que através da inserção das TIC's em sua prática pedagógica verificou melhoria na aprendizagem dos alunos nas aulas mediadas pelos recursos tecnológicos. Da mesma forma, Rodrigues (2016), apesar das dificuldades enfrentadas com a falta de estrutura da escola em que leciona, ao implantar em suas aulas projetos com o ensino híbrido, percebeu resultados positivos, como a motivação, participação dos alunos e o declínio dos índices de reprovação.

\section{Conclusões}

Percebe-se que o Ensino de História ainda é muito pautado no modelo tradicional, com base na memorização, nos fatos históricos apresentados de forma linear, factual e o professor como detentor e o centro do saber. Apesar de alguns professores serem adeptos ao uso das TIC's, inserindo-as em sua prática pedagógica, é possível perceber pelas pesquisas já realizadas as dificuldades enfrentadas pelos docentes especialmente em relação à falta de formação e a carência de recursos e infraestrutura das escolas. Além disso, muitos professores que utilizam as TIC's, acabam por manter a mesma prática pedagógica, onde o professor é o centro do saber e os alunos são sujeitos passivos, os fatos históricos dados de forma linear e factual, não havendo preocupação com a construção do conhecimento histórico. Sendo assim, não adianta o professor inserir a tecnologia enquanto sua própria prática não mudar. Ainda assim, algumas pesquisas apontam casos de professores que afirmaram perceber a potencialidade do uso das Tic's no processo de ensino e aprendizagem e a ampliação da aprendizagem de seus alunos.

Acreditamos que o uso pedagógico das tecnologias possa fazer diferença, desde que utilizadas adequadamente, tornando as aulas mais atrativas para nossas crianças, adolescentes e jovens que vivem cercados dos mais diversos aparatos tecnológicos. Os alunos mudaram, considerando as diversas informações que recebem todos os dias e o acesso aos diversos 
meios de comunicação. Eles são questionadores e ativos em sala de aula, não aceitam apenas receber informação e solicitam mais do professor, sendo assim, é necessário uma educação contextualizada, onde o professor assuma-se como mediador do processo educativo.

Muitas pesquisas na área da educação indicam as mudanças pelas quais está passando a sociedade e consequentemente as escolas. Algumas destas mudanças, em nosso ponto de vista são necessárias, para que haja compatibilidade entre ambas, a exemplo da inserção das TIC's no espaço escolar, bem como a formação do professor para incorporar as tecnologias na sua prática pedagógica, de maneira que contribua com o processo de ensino e aprendizagem

Para a disciplina de História, contamos com diversas fontes de pesquisas através da internet, filmes, jogos e diversos recursos que podem ser utilizados a fim de que os discentes sejam ativos e participativos na aprendizagem, que se motivem e que busquem o conhecimento. Por fim, é necessário que o professor compreenda as TIC's não como máquinas de ensinar, mas como como ferramentas cognitivas e como recursos para a aprendizagem e que o poder público invista na formação do professor e na infraestrutura das escolas.

\section{Referências}

ARAÚJO. Marcelo Marcos de. A utilização do mecanismo de busca do Google na pesquisa e no ensino de História: explorando possibilidades. 2017. Dissertação (Mestrado Profissional em Ensino de História). Universidade Federal de Tocantins. Araguaína-TO.

BRASIL, Ato complementar $n^{o}$ 75, 20 outubro de 1969. Disponível em HTTP:// Texto disponível em http://www.planalto.gov.br/ccivil_03/ACP/acp-75-69.htm. Acesso em $16 / 11 / 2017$

BRASIL, Lei $n^{o}$ 11.645, 10 de março de 2008. Disponível em: http://www.planalto.gov.br/ccivil_03/_Ato2007-2010/2008/Lei/L11645. Acesso em: 07/01/19

BRITO, Glaucia da Silva; PURIFICAÇÃO, Ivonélia da. Educação e novas tecnologias: um re-pensar. Curitiba, PR: Ibpex, 2006.

CARAMEZ, Cláudia Senra. A aprendizagem histórica de professores mediada pelas tecnologias de informação e comunicação : perspectivas da educação histórica. 2014. Dissertação (Mestrado em Educação). Universidade Federal do Paraná. Curitiba-PR.

CRUZ, Marília Beatriz Azevedo, $\mathrm{O}$ ensino de História no contexto das transições paradigmáticas das História e da Educação, (In) NIKITIUK, Sônia M. Leite (Org.). Repensando o ensino de história. 4 ed. São Paulo: Cortez, 2001

CRUZ, Sayonara Ribeiro Marcelino. O uso do computador na aula de História: contribuições e desafios. 2013. Dissertação (Mestrado em Educação). Universidade Federal de Lavras. Lavras- MG. 
FERNANDES, Sidneia Caetano de Alcântara. As Tecnologias de Informação e Comunicação No ensino de aprendizagem de História: possibilidades no ensino fundamental e médio. 2012. Dissertação (Mestrado em Educação). Universidade Católica Dom Bosco. Campo GrandeMS.

FONSECA, Selva Guimarães. Caminhos da história ensinada. $2^{\circ}$ edição. Campinas SP: Papirus, 1994.

FONSECA, Thais Nívia de Lima. Historia e ensino de historia. $3^{\circ}$ Ed Belo Horizonte. Autentica editora, 2011.

GONÇALVES, Carla Fernanda, Tecnologias Digitais da Informação e Comunicação no ensino e na aprendizagem de História: representações sociais de professores. 2015. 128f. Dissertação (Programa de Pós-Graduação em Educação). Pontifícia Universidade Católica de Minas Gerais, Belo Horizonte, 2015.

GUIMARÃES, Margarida Freitas. Práticas pedagógicas inovadoras no uso 1:1 do laptop educacional: mais promessa do que realidade no ensino de História. 2013. Dissertação (Mestrado em Educação). Pontifícia Universidade Católica de Minas Gerais. Belo HorizonteMG.

GUIMARÃES, Selva, Didática e prática de ensino de História: Experiências, reflexões e aprendizados. Campinas, SP: Papirus, 2015.

KARNAL, Leandro (org) História na sala de aula: conceitos, práticas e propostas. $\quad 6^{\circ}$ edição. São Paulo: Contexto, 2010

KENSKI, Vani Moreira. Educação e tecnologias: o novo ritmo da informação. Campinas-SP: Papirus, 2007

KENSKI, Vani Moreira. Novas tecnologias: o redimensionamento do espaço e do tempo e os impactos no trabalho docente. Revista Brasileira de Educação, $\mathrm{n}^{\circ}$ 8, pg 58-71, mai/jun/ago 1998.

LE GOFF, Jacques. História e memória. Campinas (SP): Ed. Unicamp, 1990.

LEIVAS, Marta. Riscos \& bordados: o ensino de História e as tecnologias de informação e comunicação. 2004. Dissertação (Mestrado em Educação). Universidade Federal do Rio Grande do Sul. Porto Alegre- RS.

LÉVY, Pierre. Cibercultura. 3. ed. São Paulo: Editora 34, 2010. 270 p. (Coleção trans) ISBN 9788573261264

MORAN, José Manuel. A educação que desejamos: Novos desafios e como chegar lá. Campinas, SP: Papirus, $4^{\circ}$ edição , 2009.

PERES, Marcus Vinícius Monteiro. Ensino de História, novas tecnologias digitais e temporalidade: uma análise discursiva de um material didático em circulação nas escolas públicas da educação básica. 2016. Dissertação (Mestrado em Educação). Universidade Federal do Rio de Janeiro. Rio de Janeiro- RJ. 
PRENSKY, M.: Digital Natives Digital Immigrants. In: PRENSKY, Marc. On the Horizon. NCB University Press, Vol. 9 No. 5, October (2001a). Disponível em <http://www.marcprensky.com/writing/Prensky\%20-\%20Digital\%20Natives, \%20

Digital\%20Immigrants\%20-\%20Part1.pdf>. Aceso em 17 jan 2018.

PINSKY, Jaime (org.) O Ensino de história e a criação do fato. $6^{\mathrm{a}}$ ed.. São Paulo: Contexto, 1994 - (Coleção Repensando o ensino).

RODRIGUES, Eric Freitas. Tecnologia, inovação e ensino de História: o ensino híbrido e suas possibilidades. 2016. Dissertação (Mestrado Profissional em Ensino de História). Universidade Federal Fluminense. Niterói-RJ

SCHIMIDT, Maria Auxiliadora, CAINELLI, Marlene. Ensinar História. São Paulo: Scipione, 2009

SIBILIA, Paula. Redes ou paredes: a escolas em tempos de dispersão. Rio de Janeiro: Contraponto, 2012

TAVARES, Luana Ciciliano. A Educação Histórica e as Mídias digitais construindo o conhecimento histórico em sala de aula. Dissertação de mestrado apresentada ao Programa de Pós-Graduação em História, Mestrado Profissional em História, pesquisa e vivências de ensino-aprendizagem, da Universidade Federal do Rio Grande - FURG, 2015.

TIMÓTEO, Herbert de Oliveira. Caderno Virtual: potencialidade das TICE no ensino e aprendizagem de História. 2012. Dissertação (Mestrado em Educação). Universidade do Estado de Minas Gerais, Belo Horizonte-MG.

TOMAZ, Márcio de Fátimo. Softwares educacionais e o ensino de História: elementos para uma análise didática. 2005. Dissertação (Mestrado em Educação). Universidade Federal do Paraná. Curitiba-PR.

VASCONCELOS JÚNIOR, Luciano Bezerra de. Concepções de práticas pedagógica evidenciadas em softwares educacionais para o ensino de História: inovação ou tradicionalismo maquiado?. 2009. Dissertação (Mestrado em Educação). Universidade Federal de Pernambuco. Recife. 